\title{
A STUDY OF RISK FACTOR PROFILE OF ATRIAL FIBRILLATION APPLYING CHA2DS2-VASC SCORE
}

\author{
Ahmed Mustafa, Imtiaz Ali Khan, Hafiza Sonia Iqbal, Anam Fatima Janjua, Faraz Ahmad, Saadat Ullah Khan, Sohail Aziz, \\ Abdul Hameed Siddiqui, Farhan Tuyyab \\ Armed Forces Institute of Cardiology/National Institute of Heart Disease (AFIC/NIHD)/National University of Medical Sciences (NUMS) \\ Rawalpindi Pakistan
}

\begin{abstract}
Objective: To identify the risk factor profile of Atrial Fibrillation applying CHA2DS2-VASC scoring system Study Design: Descriptive cross-sectional study.

Place and Duration of Study: The study was conducted in outdoor patient and emergency departments of Armed Forces Institute of Cardiology/National Institute of Heart Diseases in 4 months duration after approval of synopsis, from Sep 2019 to Dec 2019.

Methodology: All patients with symptoms of palpitation and dyspnea were evaluated with detailed history, physical examination, electrocardiogram and 2-D echocardiography for collection of data. Patients who were found with Atrial Fibrillation on electrocardiogram and non-valvular on 2-D echocardiography were enrolled. Detailed History regarding CHA2DS2-VASC scoring system was taken. Patients with age $<18$ years, those with moderate rheumatic stenos is, hypertrophic cardiomyopathy and Atrial Fibrillation with prosthetic valves were excluded. Data was entered and analyzed with SPSS-23.

Results: Out of 100 patients enrolled, frequencies of male and female patients were $60(60 \%)$ and $40(40 \%)$ respectively. The age varied from 25 years to 89 years with a mean age of $64.27 \pm 12$ years. Maximum number of patients was between 65-74 years (31\%). Hypertension (57\%) was the most common risk factor after gender followed by age. Frequencies of other risk factors were congestive heart failure (33\%), diabetes mellitus (18\%), vascular disease (14\%) and stroke/TIA/thrombo-embolism (13\%). Paroxysmal atrial fibrillation was the most common type of atrial fibrillation observed (67\%) followed by persistent atrial fibrillation (31\%). The number of patients having CHA2DS2-VASC score 2 and greater than 2 were $76(76 \%)$ and less than 2 were $24 \%$.

Conclusion: Our findings highlighted the prevalence of non-modifiable as well as modifiable predictors of thromboembolic phenomena in atrial fibrillation using CHA2DS2-VASC scoring system in our population.
\end{abstract}

Keywords: Atrial Fibrillation, CHA2DS2-VASC, Risk factor profile.

This is an Open Access article distributed under the terms of the Creative Commons Attribution License (http://creativecommons.org/licenses/by/4.0), which permits unrestricted use, distribution, and reproduction in any medium, provided the original work is properly cited.

\section{INTRODUCTION}

Atrial fibrillation is the most common sustained cardiac arrhythmia which is characterized by the degeneration of the organized electrical activity into a rapid chaotic pattern ${ }^{1}$. It accounts for approximately one third of hospitalization of cardiac rhythm disturbances ${ }^{2}$. The prevalence of atrial fibrillation is higher in men and increases with age ${ }^{3}$. Atrial fibrillation is associated with increased risk of stroke, heart failure and mortality ${ }^{4}$

Atrial fibrillation can be classified as newonset and recurrent (at least two episodes).

Correspondence: Dr Ahmed Mustafa, Cardiology Department, AFIC/NIHD, Rawalpindi Pakistan
Depending upon patterns, they can be paroxysmal (self-limiting), persistent (sustained $>7$ days), long-standing persistent (sustained $>12$ months) and permanent (no longer persuing restoration of sinus rhythm). It is also important to differentiate between valvular (rheumatic mitral stenosis, prosthetic heart valve or mitral valve repair) and non-valvular a trial fibrillation. Lone fibrillations are atrial fibrillations without any absolute cause $^{5}$.

Among the risk factors, atrial fibrillation is associated with advanced age, hypertension, valvular heart diseases, congestive heart diseases and coronary heart diseases ${ }^{6}$. Atrial fibrillation is also linked with cardiac surgeries hyperthyroidism, obstructive sleep apnea and obesity. 
Among other factors that contribute to atrial fibrillation are physiological stress, drugs and pulmonary embolism.

Patients with atrial fibrillation have a strong pre-dilection to wards increased risk of stroke7. CHA2DS-V2ASC is the risk stratification scoring system which is used to know about the risk of stroke in atrial fibrillation patients ${ }^{8}$. Factors which contribute towards CHA2DS2-VASC scoring system are diabetes mellitus, hypertension, congestive heart failure, age (greater than or equal to 75 years), stroke / TIA / thromboembolism, age (65-74 year) and female sex ${ }^{11}$. These factors mainly contribute towards stroke in atrial fibrillation patients ${ }^{9}$.

The purpose of this study is to know the risk factor profile of atrial fibrillation patients through CHA2DSV2AC so that early recognition of the patients having pre-dilection to stroke could be done. Similarly, pre-dominance of risk factor profile (predictors of warfarin use) in atrial fibrillation patients could be found out and dealt with as early as possible so that the risk of stroke may be decreased in these patients.

\section{METHODOLOGY}

The study was conducted at Armed Forces Institute of Cardiology/National Institute of Heart Diseases, Rawalpindi. A total of 100 patients with a history of atrial fibrillation (treated or not and whatever the rhythm at the time of inclusion) with at least 1 atrial fibrillation episode documented by standard ECG or by Holter ECG in the previous 12 months or documented current atrial fibrillation were enrolled. Informed written consent was taken. Data regarding age, gender, clinical presentations especially palpitations and dyspnea was collected. Other features like diabetes mellitus, hypertension, congestive heart failure, history of stroke and vascular diseases were also noted in the history. Detailed physical examination was done. Laboratory tests including $\mathrm{CBC}$, metabolic status, magnesium levels and thyroid function tests were performed. ECG obtained was evaluated from electrophysiology department for confirmation of diagnosis (Abs- ence of $p$-waves and replaced by fibrillatory $\mathrm{f}$ waves, ventricular rate is irregularly irregular). 2-D echocardiography was done to know about ejection fraction, mitral valve disease, left atrial size and pulmonary hypertension. Exclusion criteria included patients who were unable to perform written informed consent, mental disability such as dementia or significant mental disability. Similarly, Patients with age less than 18 years, those with moderate rheumatic stenosis, hypertrophic cardiomyopathy and Atrial fibrillation with prosthetic valves were ruled out. Congestive heart failure was defined as patients with ejection fraction $<40 \%$. Hypertension was defined as blood pressure $>140 / 90$ or even less than 140/ 90 with medication. Among age groups, people with age groups between 18-90 years were included. Diabetes mellitus was defined as patients with deranged blood sugar status i.e. fasting blood sugar level greater than $110 \mathrm{mg} / \mathrm{dl}$ and random blood sugar level greater than $180 \mathrm{mg} / \mathrm{dl}$ and $\mathrm{HbA} 1 \mathrm{C}$ levels greater than $6.5 \%$. Stroke was defined as any history of ischaemic cerebrovascular accident, haemorrhagic cerebrovascular accident, transient ischaemic attack or thromboembolic phenomena. Vascular disease was defined as any history of prior myocardial infarction, peripheral arterial disease or aortic plaque. Female sex (if age $<65$ years with no other risk factors, female sex independently does not increase risk). CHA2DS2-VASC is a risk stratification scoring system which is used for the assessment of stroke risk in patients with non- valvular atrial fibrillation ${ }^{10-12}$. This scoring system is a follows

$\begin{array}{lc}\text { Clinical Features } & \text { Score } \\ \text { Congestive heart failure }(\mathrm{EF}<40 \%) & 1 \\ \text { Hypertension }(\mathrm{BP}>140 / 90) & 1 \\ \text { Age }(\geq 75 \text { years }) & 2 \\ \text { Diabetes Mellitus } & 1 \\ \text { Stroke/TIA/Thromboembolism } & 2 \\ \text { Vascular disease } & 1 \\ \text { Age }(65-74 \text { years }) & 1 \\ \text { Gender (female) } & 1 \\ \text { Total scores } & 9\end{array}$


Anti-thrombotic therapy is started on the basis of scoring system

Patients with score 0 are reasonable to omit any anti-thrombotic therapy (class-2a)

Patients with score 1 need no therapy or oral anti-coagulation or aspirin (class-2b)

Patients with score greater than or equal to 2 need anti-coagulation therapy (class-1)

All data was handled with care to maintain patient confidentiality. The data was analyzed with SPSS-23. Frequencies of different risk factors were calculated in terms of percentages. Population characteristics were summarized as SD for continuous variables and as percentages for qualitative variables.

\section{RESULTS}

Out of 100 patients enrolled, 60 were male $(60 \%)$ and 40 were female $(40 \%)$ which revealed a relatively higher burden of atrial fibrillation in males as compared to females. Age varied from

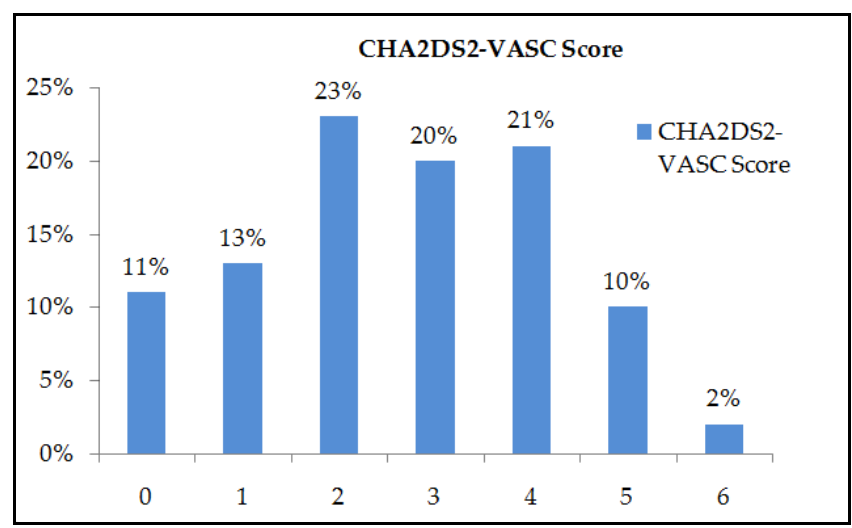

Figure: Percentage distribution of CHA2DS2-VASC score among patients with atrial fibrillation.

25 to 89 years with mean age $64.27 \pm 12$ years. Maximum number of patients i.e. 31 (31\%) were between 65-74 years while a significant number of patients were either greater than or equal to 75 years $(27 \%)$. Frequency of patients between $56-64$ years was $23 \%$ while 8 (8\%) were between $46-55$ years of age. There were $7(7 \%)$ patients between $36-45$ years of age while in younger age group i.e. below and equal to 35 years were only 4 patients $(4 \%)$.
Among the modifiable risk factors, hypertension is the most common risk factor $(57 \%)$ followed by congestive heart failure (33\%). Among other risk factors diabetes mellitus is the 3rd most common (18\%). Vascular diseases and stroke are present in $14 \%$ and $13 \%$ respectively.

Paroxysmal atrial fibrillation was the most common type of atrial fibrillation observed (67\%) followed by persistent atrial fibrillation (31\%). Whereas, long standing persistent and atypical flutter were present in $1 \%$ patients each. The data discussed above is evident in the following frequency (table-I).

\section{Table-I: Clinical characteristics of atrial fibrillation} ( $n=100)$.

\begin{tabular}{|c|c|c|c|}
\hline $\begin{array}{l}\text { S. } \\
\text { No. }\end{array}$ & \multicolumn{2}{|l|}{ Variables } & Percentages \\
\hline 1 & \multicolumn{2}{|c|}{ Age (Mean \pm SD) } & $\begin{array}{c}64.27 \pm \\
12.808 \text { years }\end{array}$ \\
\hline & \multirow{6}{*}{ Age Groups } & $\leq 35$ years & $4 \%$ \\
\hline & & $36-45$ years & $7 \%$ \\
\hline & & $46-55$ years & $8 \%$ \\
\hline & & 56-64 years & $23 \%$ \\
\hline & & $65-74$ years & $31 \%$ \\
\hline & & $\geq 75$ years & $27 \%$ \\
\hline \multirow{2}{*}{2} & \multirow{2}{*}{ Gender Risk } & Female & $40 \%$ \\
\hline & & Male & $60 \%$ \\
\hline 3 & \multicolumn{2}{|c|}{ Hypertension risk } & $57 \%$ \\
\hline 4 & \multicolumn{2}{|l|}{ Age Risk } & $55 \%$ \\
\hline 5 & \multicolumn{2}{|c|}{ Congestive Heart Failure risk } & $33 \%$ \\
\hline 6 & \multicolumn{2}{|c|}{ Vascular diseases } & $14 \%$ \\
\hline 7 & \multicolumn{2}{|c|}{ Stroke, TIA, Embolism } & $13 \%$ \\
\hline 8 & \multicolumn{2}{|c|}{ Diabetes Miletus } & $18 \%$ \\
\hline \multirow{4}{*}{9} & \multirow{4}{*}{$\begin{array}{l}\text { Atrial } \\
\text { fibrillation } \\
\text { classification }\end{array}$} & Paroxysmal & $67 \%$ \\
\hline & & Persistent & $31 \%$ \\
\hline & & Permanent & $1 \%$ \\
\hline & & $\begin{array}{l}\text { Atypical } \\
\text { flutter }\end{array}$ & $1 \%$ \\
\hline
\end{tabular}

The number of patients having CHA2DS2VASC score 2 and greater than 2 are $76(76 \%)$ whereas number of patients scoring $>2$ are 13 (13\%). Among them 2, 3, 4, 5, 6 CHA2DS2-VASC score are $23(23 \%), 20(20 \%), 21(21 \%), 10(10), 2$ (2\%) respectively. Similarly, number of patients having 0 CHA2DS2-VASC score are $11(11 \%)$. As is evident in the following graph (figure). 


\section{DISCUSSION}

The current study helped us to identify the prevalence of risk factors of atrial fibrillation in our local population, especially in people who are more prone to thrombo-embolic phenomena having higher CHA2DS2-VASC score. Like other countries, Pakistan is undergoing transition from communicable to non-communicable diseases and atrial fibrillation is a non-communicable disease. Among the non-modifiable risk factors, age was considered as the most important risk factor. As in our study, mean of age of presentation is $64.27 \pm 12$ years as compared to study conducted in Germany where mean age of presentation was $55 \pm 5$ years $^{21}$. Second non-modifiable risk factor is gender. As we can see through results that major percentage of our study population is male $21,22,12,13$. Female sex is considered to be an independent risk factor for thromboembolic phenomena ${ }^{10-13}$. This finding of gender distribution is also in line with published data on prevalence of atrial fibrillation by Framingham Heart Studies ${ }^{11}$. However, in contrast, sex is not as independent predictor of all cause stroke in the Framingham Heart Study model ${ }^{11}$.

Hypertension is among the modifiable risk factors which is most common among individuals. Especially, elderly age $>75$ years and hypertension when combined play a significant role to increase risk of stroke ${ }^{10}$. This study is validated by American Heart Association guidelines ${ }^{11-15}$. Among the other risk factors, congestive heart failure $(33 \%)$ was the $2^{\text {nd }}$ most common risk factor followed by diabetes (18\%), vascular phenomena (14\%) and stroke/TIA/Thromboembolism (13\%). The most interesting studies on the predictors of warfarin use in non-valvular atrial fibrillation patients are those by Go et $a l^{2}$. Other investigators analyzed the positive and negative predictors of warfarin use in non-valvular atrial fibrillation. These studies revealed that a history of stroke and advanced age are independent predictors of warfarin use ${ }^{2}$. As we can see in the above mentioned graph that CHA2DS2-VASC score of most of the patients is either 2 or greater than 2 which is a main indication for anti-thrombotic therapy in these patients ${ }^{16}$. There are a significant number of patients which have either 0 score $(11 \%)$ or 1 score $(13 \%)$ which indicates that risk factor profile of atrial fibrillation is beyond above discussed factors ${ }^{17-20}$. Atrial fibrillation itself is a major cause of heart failure in vascular diseases ${ }^{20}$. Other risk factors like asthma, chronic kidney disease also contribute to atrial fibrillation ${ }^{21}$ but the variables discussed under the study are considered to be the main predictors of stroke and anti-thrombotic therapy in non-valvular atrial fibrillation ${ }^{21-22}$.

Limitations to my study are that data is very small. Although we increased the sample size as compared to that calculated through prevalence $(2.7 \%)^{21}$ but even then, this was not large enough as compared to studies conducted in other countries. 2nd limitation is that patients with atrial fibrillation should be followed to study the stroke risk for prolonged period of time but this is not possible in our setting. As this is a single center study, therefore, results may not be generalized to other clinical settings.

\section{CONCLUSION}

Our findings highlight the relative prevalence of different risk factors of atrial fibrillation in our local population especially those risk factors present in CHA2DS2-VASC score contributing towards thromboembolic phenomena. Apart from prevalence of non-modifiable risk factors, we have a great number of patients with modifiable risk factors i.e. stroke, hypertension and diabetes mellitus. It is observed that adults with combinations of heart failure, hypertension, diabetes, advanced age and coronary artery disease are at higher risk of paroxysmal atrial fibrillation $^{21}$. Risks associated with combinations are not always additive ${ }^{22}$. Rather, certain risk factors like advanced age (age greater than 75 years) and hypertension in particular are both prevalent and high risk 22 , contributing substantially to the incidence of atrial fibrillation. This also shows that a great number of our local population is becoming victim to atrial fibrillation because of sedentary life style. Therefore, there is need to conduct public awareness programs to make people aware of 
these modifiable risk factors. Community based measures for screening and primary prevention should be implemented with emphasis on life style modification and younger population in particular should be motivated to adopt healthy life style behaviour to combat the globally increasing burden of atrial fibrillation as well as to limit the financial burden on country economy due to increasing disease prevalence. Patients having higher CHA2DS2-VASc score should especially be educated to modify their life style and ensure medicine compliance to decrease thromboembolic phenomena.

\section{CONFLICT OF INTEREST}

This study has no conflict of interest to be declared by any author.

\section{REFERENCES}

1. Tse HF, Wang YJ, Ahmed Ai-Abdullah M, Pizarro-Borromeo AB, Chiang CE, Krittayaphong R.. Stroke prevention in atrial fibrillationAn Asian stroke perspective. Heart Rhythm 2013; 10(7): 1082-88.

2. Go AS, Hylek EM, Phillips KA, Chang Y, Henault LE, Selby JV, et al. Prevalence of diagnosed atrial fibrillation in adults: national implications for rhythm management and stroke prevention: the an ticoagulation and risk factors in atrial fibrillation (ATRIA) study. J Am Med Assoc 2001; 285(18): 2370-75.

3. Akao M, Chun YH, Wada H. Current status of clinical background of patients with atrial fibrillation in a community-based survey: the Fushimi AF Registry. J Cardiol 2013; 61(4): 260-66.

4. Zuo ML, Liu S, Chan KH, Lau KK, Chong BH, Lam KF, et al. The CHADS2 and CHA 2DS 2-VASc scores predict new occurrence of atrial fibrillation and ischemic stroke. J Interv Card Electrophysiol 2013; 37(1): 47-54.

5. Samol A, Masin M, Gellner R, Otte B, Pavenstadt HJ, Ringelstein EB, et al. Prevalence of unknown atrial fibrillation in patients with risk factors. Europace 2013; 15(1): 657-62.

6. Ziegler PD, Glotzer TV, Daoud EG, Singer DE, Ezekowitz MD, Hoyt $\mathrm{RH}$, et al. Detection of previously undiagnosed atrial fibrillation in patients with stroke risk factors and usefulness of continuous monitoring in primary stroke prevention. Am J Cardiol 2012; 110(1): 1309-14.

7. Liao JZ, Scallan C, Morillo C, O'Donnell M. Noninvasive cardiac monitoring for detecting paroxysmal atrial fibrillation or flutter after acute ischemic stroke: A systematic review. Stroke 2007; 38(11): 2935-40.

8. Lip GY, Nieuwlaat R, Pisters R, Lane DA, Crijns HJ. Refining clinical risk stratification for predicting stroke and thromboembolism in atrial fibrillation using a novel risk factor-based approach: The Euro heart survey on atrial fibrillation. Chest 2010; 137(2): 263-72.
9. Gage BF, Waterman AD, Shannon W, Boechler M, Rich MW. Validation of clinical classification schemes for predicting stroke: Results from the national registry of atrial fibrillation. J Am Med Assoc 2001; 285(22): 2864-70.

10. Fuster V, Ryden LE, Cannom DS, Crijns HJ, Curtis AB, Ellenbogen KA, et al. ACC/AHA/ESC 2006 guidelines for the management of patients with atrial fibrillation: A report of the American College of Cardiology/American Heart Association Task Force on Practice Guidelines and the European Society of Cardiology Committee for Practice Guidelines (Writing Committee to Revise the 2001 Guidelines for the Management of Patients with Atrial Fibrillation): Developed in collaboration with the European Heart Rhythm Association and the Heart Rhythm Society. Circulation 2006; 114(7): e257-e354.

11. Camm AJ, Lip GY, De Caterina R, Savelieva I, Atar D, Hohnloser SH, Hindricks G, et al. 2012 focused update of the ESC guidelines for the management of atrial fibrillation: An update of the 2010 ESC Guidelines for the management of atrial fibrillation-developed with the special contribution of the European Heart Rhythm Association. Europace 2012; 14(7): 1385-413.

12. Lip GY, Tse HF, Lane DA. Atrial fibrillation. Lancet 2012; 379(9816): 648-61.

13. Schnabel RB, Sullivan LM, Levy D, Pencina MJ, Massaro JM, D' Agostino RB, et al. Development of a risk score for atrial fibrillation (Framingham Heart Study): A community-based cohort study. Lancet 2009; 373(9665): 739-45.

14. Vos CB, Pisters R, Nieuwlaat R, Prins MH, Tieleman RG, Coelen RJ, et al. Progression from paroxysmal to persistent atrial fibrillation clinical correlates and prognosis. J Am Coll Cardiol 2010; 55(8): 725-31.

15. Kirchhof P, Breithardt G, Aliot E, Khatib SA, Apostolakis S, Auricchio A, et al. Personalized management of atrial fibrillation: Proceedings from the fourth Atrial fibrillation competence NET work/European heart rhythm association consensus conference. Europace 2013; 15(11): 1540-56.

16. Benjamin EJ, Wolf PA, D'Agostino RB, Silbershatz H, Kannel WB, Levy D. Impact of atrial fibrillation on the risk of death: The Framingham Heart Study. Circulation 1998; 98(10): 946-52.

17. Procter EK, Simon S, Horowitz, John D. New-onset atrial fibrillation and thromboembolic risk: Cardiovascular syzygy. Heart Rhythm 2016; 13(6): 1355-61.

18. Alhadramy O, Jeerakathil TJ, Majumdar SR, Najjar E, Choy J, Saqqur M. Prevalence and predictors of paroxysmal atrial fibrillation on Holter monitor in patients with stroke or transient ischemic attack. Stroke 2010; 41(11): 2596-600.

19. Elezi S, Qerkini G, Bujupi L, Shabani D, Bajraktari G. Management and comorbidities of atrial fibrillation in patients admitted in cardiology service in Kosovo - a single centre study. Anadolu Cardiol Derg 2010; 10(1): 36-40.

20. Brophy MT, Snyder KE, Gaehde S, Ives C, Gagnon D, Fiore LD. Anticoagulant use for atrial fibrillation in the elderly. J Am Geriatr Soc 2004; 52(1): 1151-56.

21. Schnabel RB, Wilde S, Wild PS, Munzel T, Blankenberg S. Atrial fibrillation: its prevalence and risk factor profile in the German general population. Dtsch Arztebl Int 2012; 109(16): 293-99.

22. Faruk ERTAŞ, Hasan KAYA. Predictors of warfarin use in patients with non-valvular atrial fibrillation who presented to the cardiology outpatient clinic of a tertiary hospital in Turkey: an observational study. Turk J Med Sci 2012; 42 (Suppl-1): 1172-79. 